\title{
Laminin Position as One of the Important Components of the Extracellular Matrix in Tissue
}

\section{Engineering of Nervous System}

Shahin Mohammad Sadeghi ${ }^{1,2}$, Sajad Sahab Negah ${ }^{1,3}$, Zabihollah Khaksar $^{3}$ *, Hadi Kazemi ${ }^{1,4}$, Hadi Aligholi $^{1,5}$ * $^{\text {* }}$

${ }^{1}$ Shefa Neuroscience Research Center, Khatam-al-Anbia Hospital, Tehran, Iran.

${ }^{2}$ Plastic Surgery Group, Medical Faculty, Shahid Beheshti University, Tehran, Iran.

${ }^{3}$ Histology and Embryology group, Basic Science Department, Faculty of Veterinary Medicine, Shiraz University, Shiraz, Iran.

${ }^{4}$ Pediatric Department, Medical Faculty, Shahed University, Tehran, Iran.

${ }^{5}$ School of Advanced Technologies in Medicine, Tehran University of Medical Sciences, Tehran, Iran.

\section{Article Info:}

\section{ABSTRACT}

ntroduction: Brain damage is often irreversible due to poor brain's self-repairing

ability. New treatment strategies focused on stem cell therapy and 3-dimension matrix for brain tissue injury. The extracellular matrix (ECM) of animal tissues is a complex mixture of macromolecules that play an essential instructional role in the development of tissues and organs. Therefore, tissue engineering approaches rely on the need to present the correct cues to cells and to guide them to maintain tissue-specific functions. Recent research efforts on ECM have showed various sequences and motifs, which play key roles in improvement of the brain function after injury. Conclusion: Small motif from ECM molecules can mimic some of the biological functions of their large molecules. Peptides sequences and motifs laminin can be linked to various biomaterials scaffolds and provide the cells with mechanical support. This may ensure appropriate cell growth that aids the formation of the correct tissue structure.

* Corresponding Authors: Zabihollah Khaksar, Hadi Aligholi

E-mail:khaksar@sirazu.ac.ir,hadialigholi@yahoo.com 
جايگًاه لامينين به عنوان يكى از اجزاى مههم ماتريكس خارج سلولى در مهندسى بافت سيستم عصبى

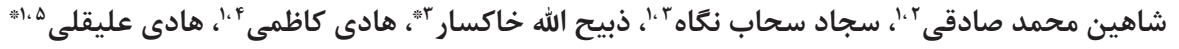

'مركز تحقيقات علوم اعصاب شفا، بيمارستان خاتم الانبياء، تهران، ايران.

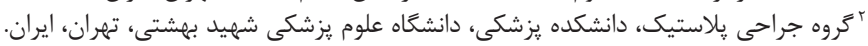

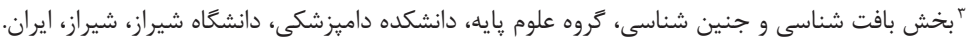

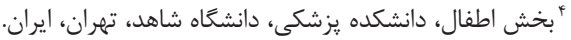

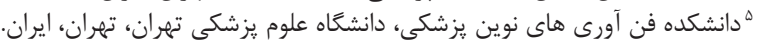

كليد وازه ها:

( إمينين

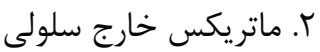

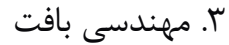

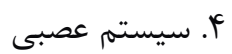

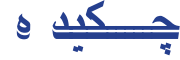

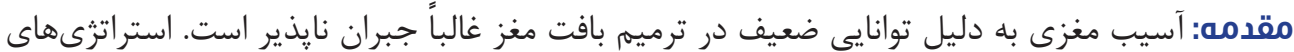

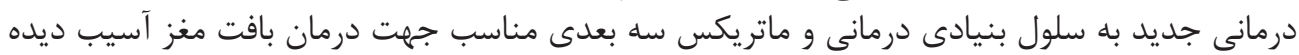

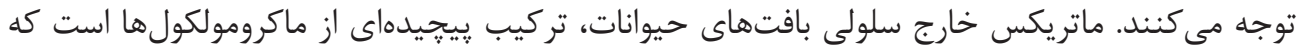

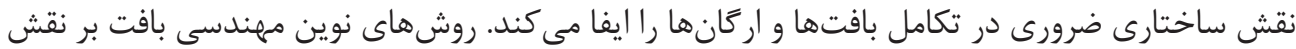

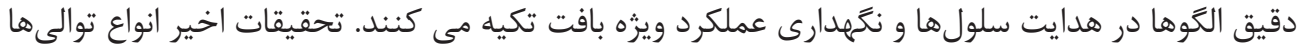

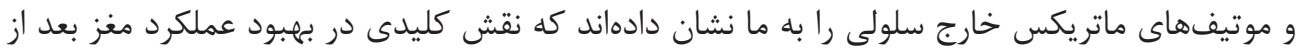

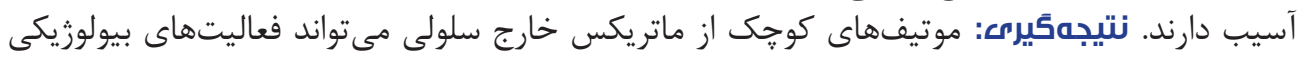

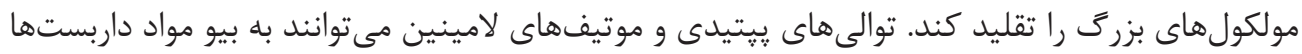

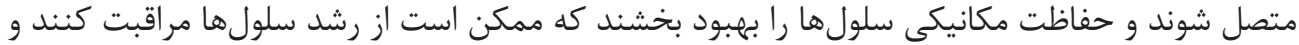
به تشكيل دقيق ساختار بافتى كمك نمايند.

" "نويسندكًان مسئول: ذبيح الله خاكسار، هادى عليقلى آدرس الكترونيكى: khaksar@shirazu.ac.ir,hadialigholi@yahoo.com 


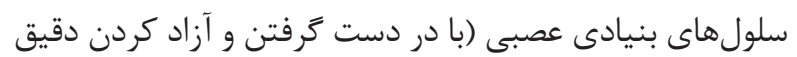

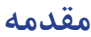

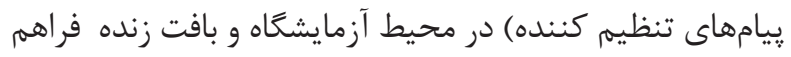

$$
\text { كند (11، • (1). }
$$

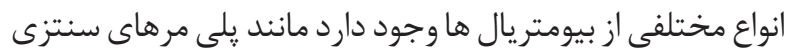

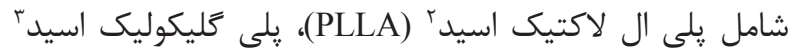
(PGA)

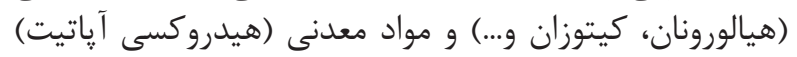

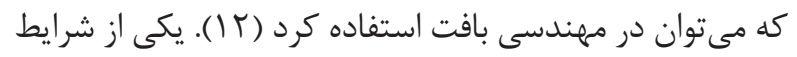

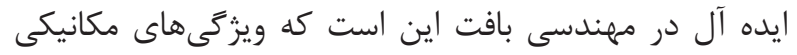

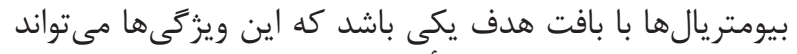

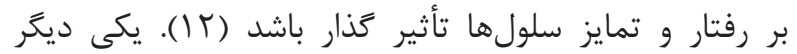

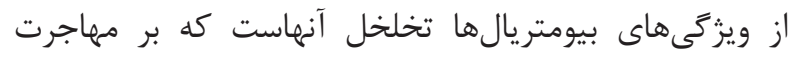

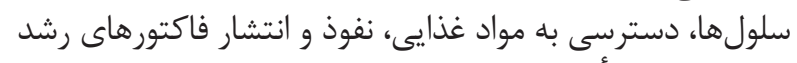

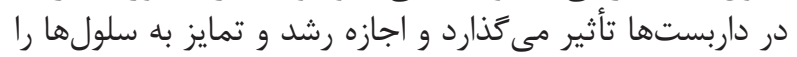

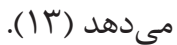

بيومتريالهايى از قبيل PLLA، بيويلىمرهاى PGA، مشهاى

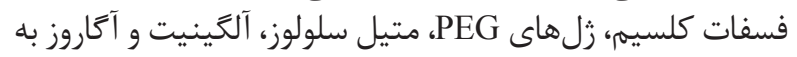

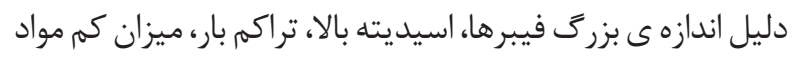

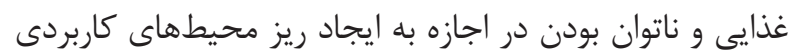

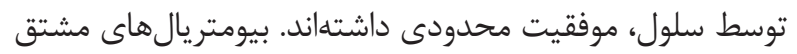

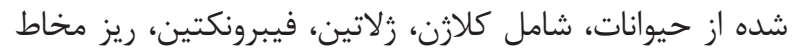

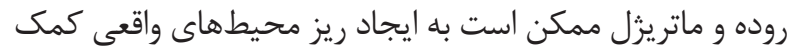

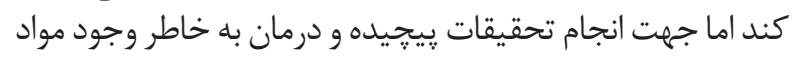

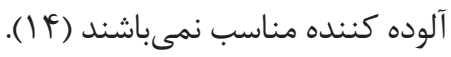

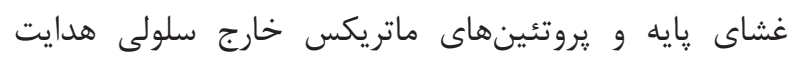

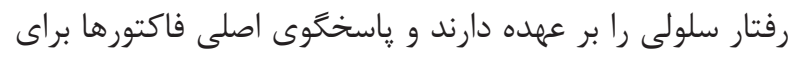

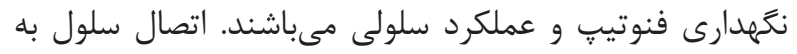

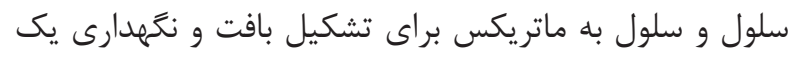

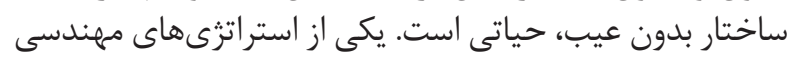

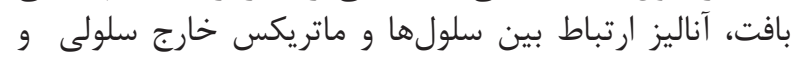
مطالعه تغييرات رفتار سلولى مىباشد.

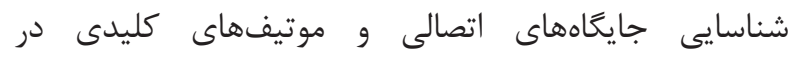

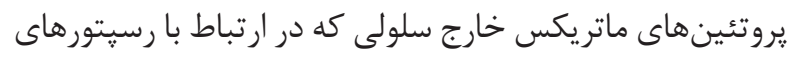

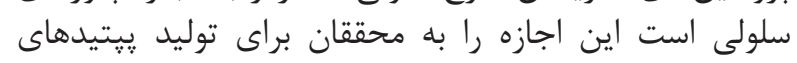

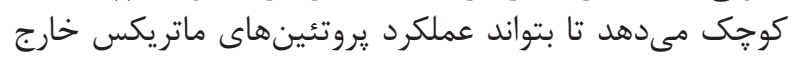

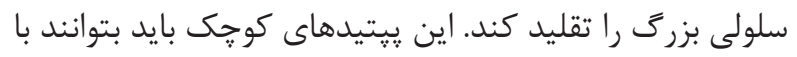

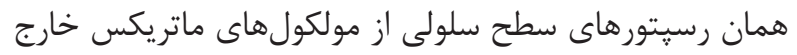

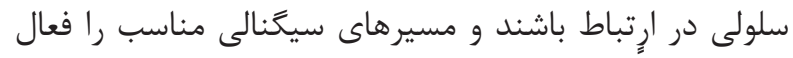
كنند و دائماً با فنوتيب سلولى بائلى در تماس باشند.

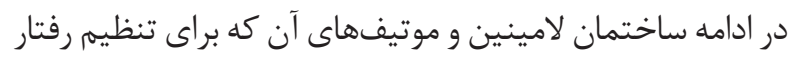
سلولى در مهندسى بافت استفاده شدهاند را توضيح مى دهين دهيم.

ساختار لامينين

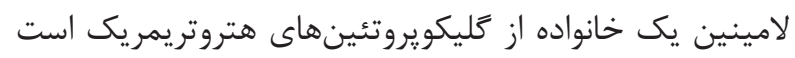

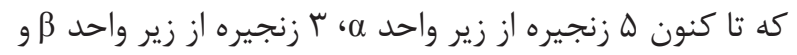

${ }_{2}^{1}$ Niche

${ }^{2}$ Poly(L-lactic acid)

${ }^{3}$ Polyglycolic acid

${ }^{4}$ Polyethylene glycol
ماتريكس خارج سلولى از مهمترين اجزاى كنام' سلولهاى

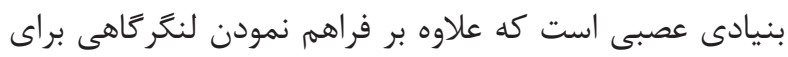

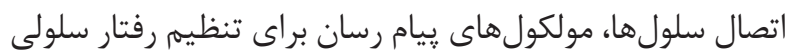

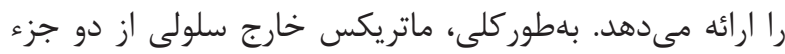

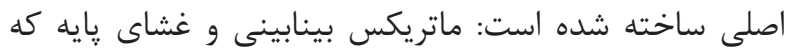

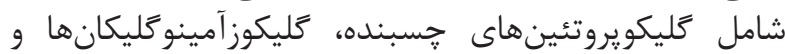

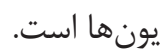

ماتريكس بينابينى در ماتريكس خارج سلولى مغز از شبكه سه كانه

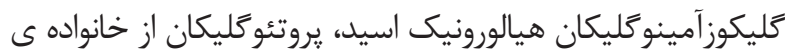

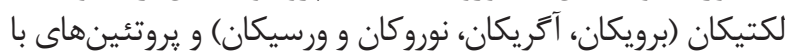

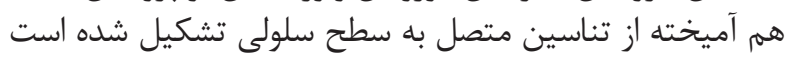

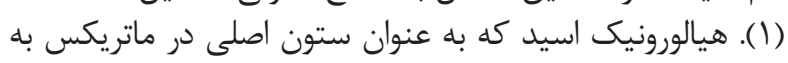

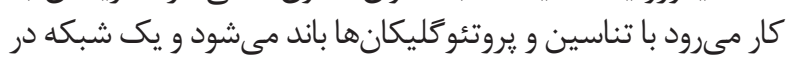

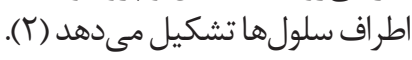

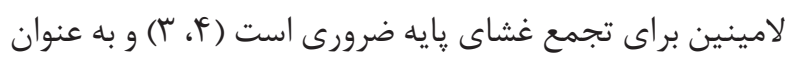

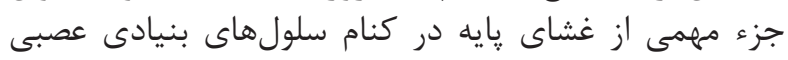

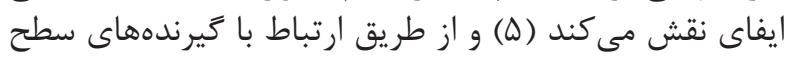

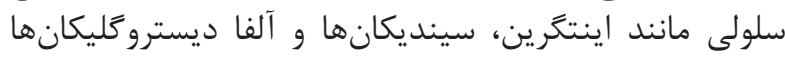

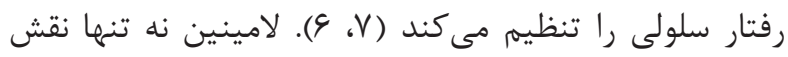

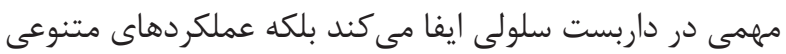

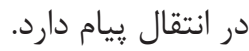
هر سلول بنيادى دست كم از سه منبع متفاوت بيام دريافت درد

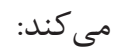

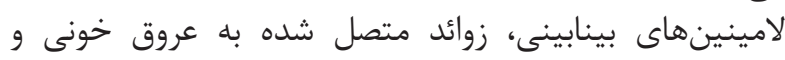

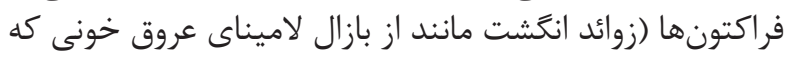

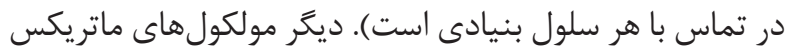

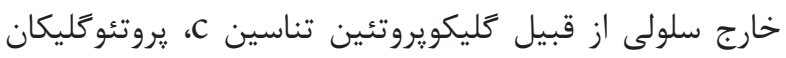

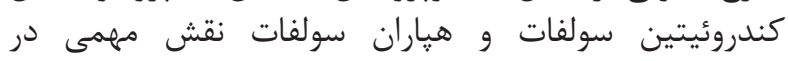

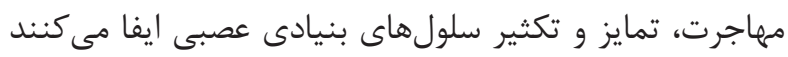

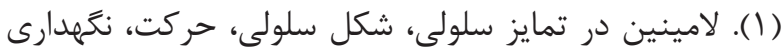

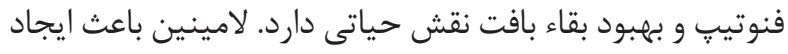

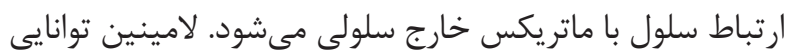

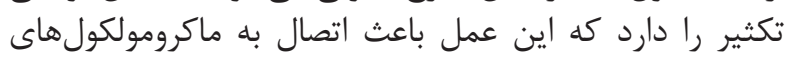

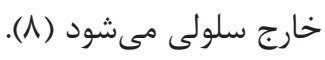
بازسازى ماتر يكس خارج سلولى براى كاربر دهاى مهيندسى بافت الت

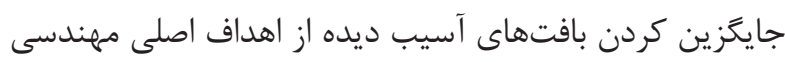

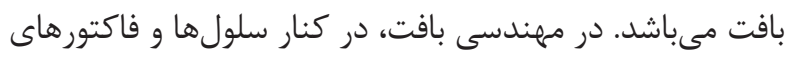

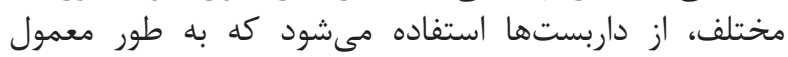

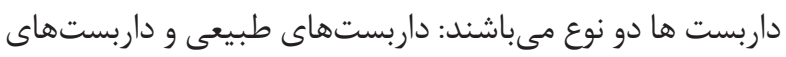

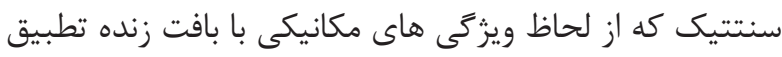

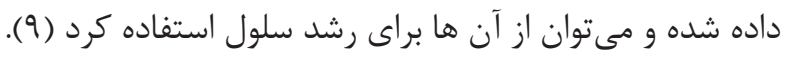
استفاده از بيومتريال ها و هيدروزل هاى تزريقى ويزه، ممكن است

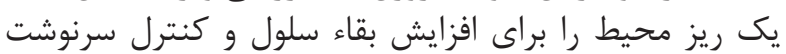


جدول |- زير واحد هاى لامينين و يراكندكى آن در بافتهاى مختلف (A).

\begin{tabular}{|c|c|}
\hline 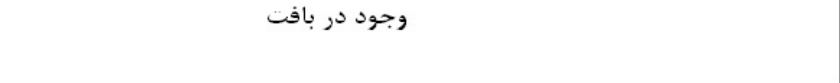 & زلامينبن واحد \\
\hline |روبان اوليه، كليه جنين و نوزاد، نورور تينا و مغز، & $\alpha_{1}$ \\
\hline عضلات قلبى و اسكلتى، عصب محبطى، موبركىها، جفت، مغز و نيكر بافتها & $\alpha_{r}$ \\
\hline بوست و ديكر استلبومهاا & $\alpha_{r}$ \\
\hline سلول هاى مزانشيمى اوليه، عضلات، عصب، ربه، عروق خونى و ديكر بافتهاى بالغ & $\alpha_{*}$ \\
\hline انواع استلبومها، كليه، عضله و عصب در حال تكامل، سينا بس غشاى بايه & $\alpha_{\Delta}$ \\
\hline |خلب بافتها & $\beta$, \\
\hline ا انصال عصبعى - عضلانى، كلومرولوس & $\beta_{r}$ \\
\hline بوست و سابر ابتلبومها & $\beta_{r}$ \\
\hline اخلب بافتها & $\gamma_{1}$ \\
\hline بوست و ساير ابتلبومها & $\gamma_{r}$ \\
\hline عصب، ابتلبوم و مغز، در غشاى بايه وجود ندارد & $\gamma_{r}$ \\
\hline
\end{tabular}

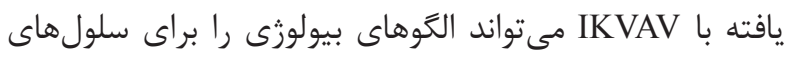

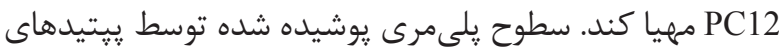

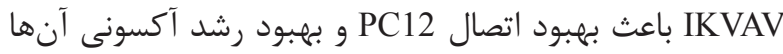

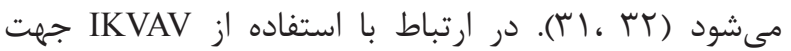

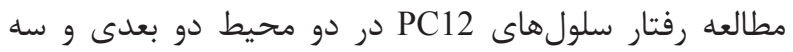

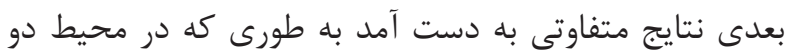

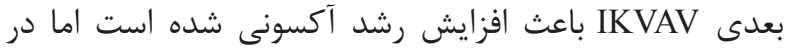

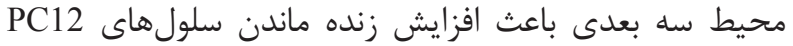

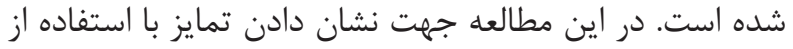

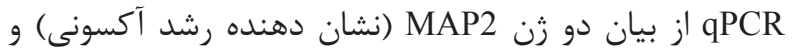

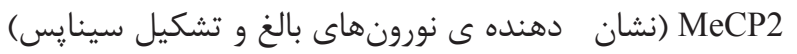

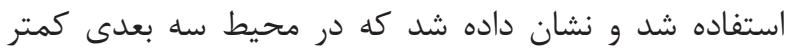

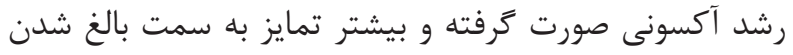
نورونها بوده است.

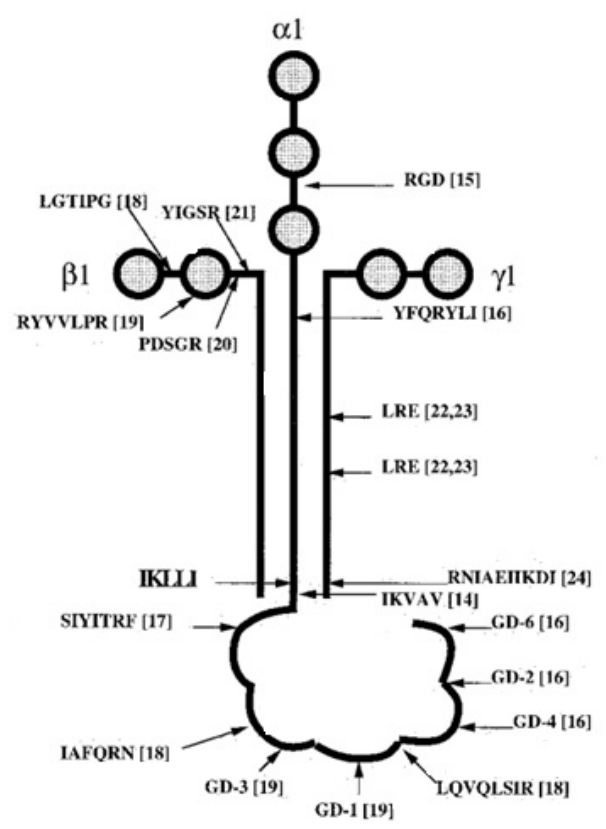

تصوير 1- مدل ساختارى از لامينين-11 11 و محلهاى اتصال سلولى (צ؟).

\footnotetext{
${ }^{5}$ Tyr-Ile-Gly-Ser-Arg
}

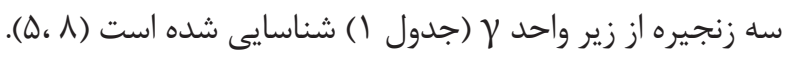

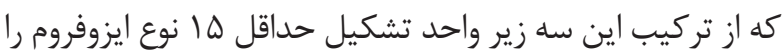
خواهيم داشت (19 ، 1 (1).

لامينين ا شامل سه زنجيره,

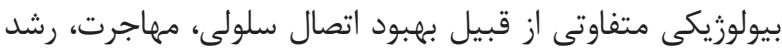

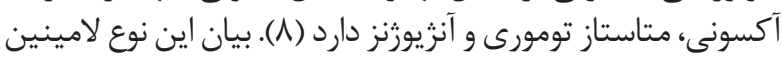

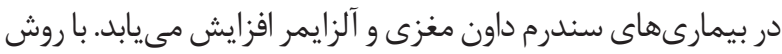

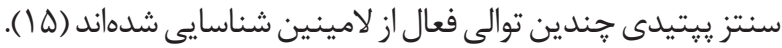

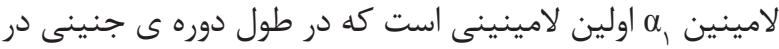

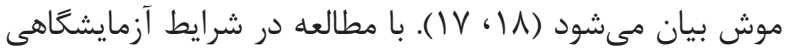

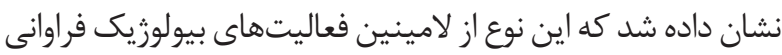

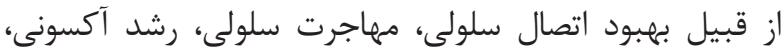

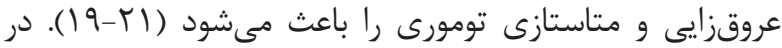

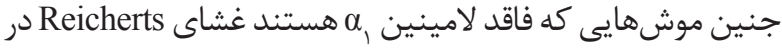

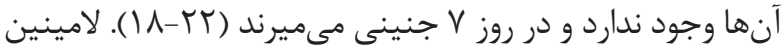

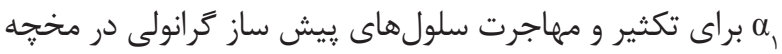

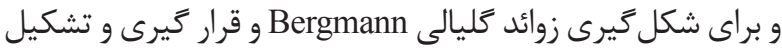

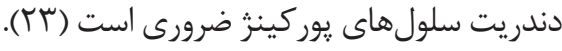
توالىهاى آمينو اسيدى YIGSR و IKVAV در لامينين توالى آمينواسيدى YIGSR (تيروزين، ايزولوسين، كَليسين،

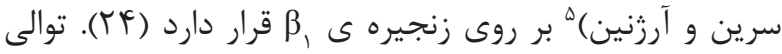

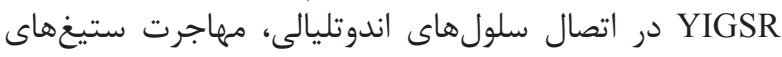

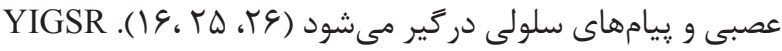

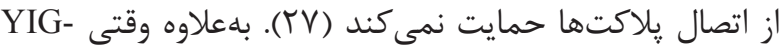

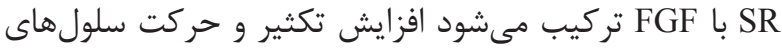

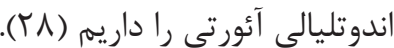

IKVAV

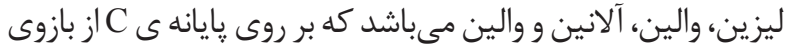

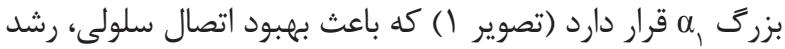

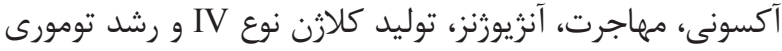

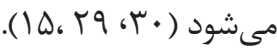
در مطالعات كذشته نشان دادند كه بيومتريالهاى تغيير شكل 
راه اميد بخش براى درمان آسيبهاى مغزى است. استفاده از

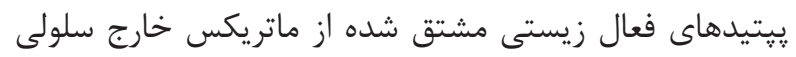

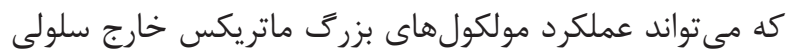

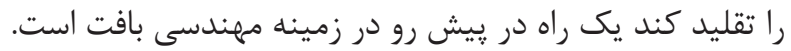

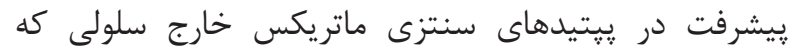

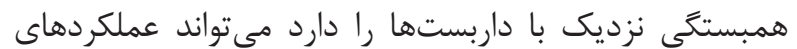

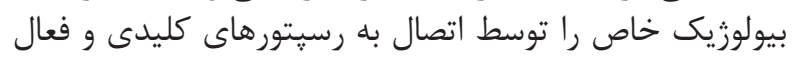

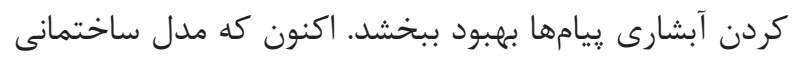

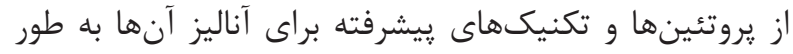

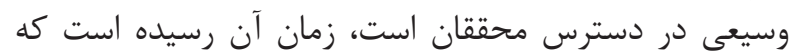

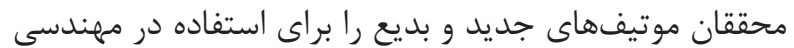
بافت كشف كنند و بكار كيرند.

1. Yao S, Liu X, Wang X, Merolli A, Chen X, Cui F. Directing neural stem cell fate with biomaterial parameters for injured brain regeneration. Prog Nat Sci. 2013; 23: 103-12.

2. Ruoslahti E. Brain extracellular matrix. Glycobiology. 1996; 6(5): 489-92.

3. Li S, Edgar D, Fässler R, Wadsworth W, Yurchenco $\mathrm{PD}$. The role of laminin in embryonic cell polarization and tissue organization. Dev Cell. 2003; 4(5): 613-24.

4. Li S, Liquari P, McKee KK, Harrison D, Patel R, Lee $\mathrm{S}$, et al. Laminin-sulfatide binding initiates basement membrane assembly and enables receptor signaling in Schwann cells and fibroblasts. J Cell Biol. 2005; 169(1): 179-89.

5. Kazanis I. Extracellular matrix and the neural stem cell niche. Dev Neurobiol. 2011; 71(11): 1006-17.

6. Gullberg D, Ekblom P. Extracellular matrix and its receptors during development. Int J Dev Biol. 1995; 39(5): 845 .

7. Miner JH, Yurchenco PD. Laminin functions in tissue morphogenesis. Annu Rev Cell Dev Biol. 2004; 20: $255-84$.

8. Colognato H, Yurchenco PD. Form and function: the laminin family of heterotrimers. Dev Dyn. 2000; 218(2): 213-34

9. Pradhan S, Farach-Carson MC. Mining the extracellular matrix for tissue engineering applications. Regen Med. 2010; 5(6): 961-70.

10. Nisbet DR, Crompton KE, Horne MK, Finkelstein

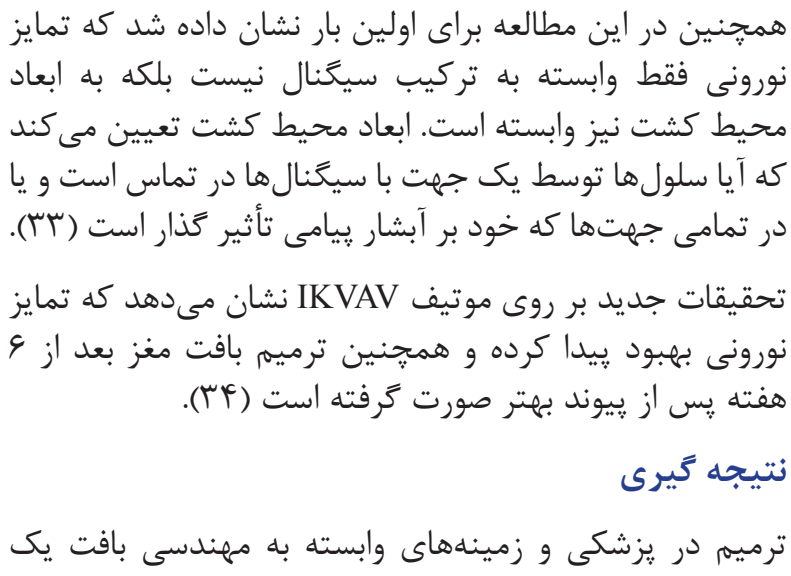

منابع

DI, Forsythe JS. Neural tissue engineering of the CNS using hydrogels. J Appl Biomater. 2008; 87(1): 251-63.

11. Potter W, Kalil RE, Kao WJ. Biomimetic material systems for neural progenitor cell-based therapy. Front Biosc. 2008; 13: 806.

12. Kohane DS, Langer R. Polymeric biomaterials in tissue engineering. Pediatr Res. 2008; 63(5): 487-91.

13. Sisson K, Zhang C, Farach-Carson MC, Chase DB, Rabolt JF. Evaluation of cross-linking methods for electrospun gelatin on cell growth and viability. Biomacromolecules. 2009; 10(7): 1675-80.

14. Zhang S, Gelain F, Zhao X. Designer self-assem bling peptide nanofiber scaffolds for 3D tissue cell cultures. Semin Cancer Biol. 2005; 15(5): 413-20.

15. Yamada M, Kadoya Y, Kasai S, Kato K, Mochizuki M, Nishi N, et al. Ile-Lys-Val-Ala-Val (IKVAV)containing lamininK1 chain peptides formamyloidlike brils. Febs Lett. 2002; 530(1-3): 48-52.

16. Aumailley M, Bruckner-Tuderman L, Carter WG, Deutzmann R, Edgar D, Ekblom P, et al. A simplified laminin nomenclature. Matrix biol. 2005; 24(5): 326-32.

17. Smyth N, Vatansever HS, Murray P, Meyer M, Frie $\mathrm{C}$, Paulsson $\mathrm{M}$, et al. Absence of basement membranes after targeting the LAMC1 gene results in embryonic lethality due to failure of endoderm differentiation. J Cell Biol. 1999; 144(1): 151-60.

18. Miner JH, Li C, Mudd JL, Go G, Sutherland AE. Compositional and structural requirements for laminin and basement membranes during mouse embryo implantation and gastrulation. Development. 2004; 131(10): 2247-56. 


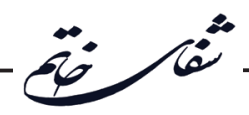

19. Kleinman HK, Sephel GC, Tashiro KI, Weeks BS, Burrous BA, Adler SH, et al. Laminin in neuronal development. Ann N Y Acad Sci. 1990; 580(1): 302-10.

20. Ekblom P, Lonai P, Talts JF. Expression and biological role of laminin-1. Matrix Biol. 2003; 22(1): $35-47$.

21. Ichikawa N, Iwabuchi $\mathrm{K}$, Kurihara H, Ishii $\mathrm{K}$, Kobayashi T, Sasaki T, et al. Binding of laminin-1 to monosialoganglioside GM1 in lipid rafts is crucial for neurite outgrowth. J Cell Sci. 2009; 122(2): 289-99.

22. Alpy F, Jivkov I, Sorokin L, Klein A, Arnold C, Huss $\mathrm{Y}$, et al. Generation of a conditionally null allele of the laminin $\alpha 1$ gene. Genesis. 2005; 43(2): 59-70.

23. Ichikawa-Tomikawa N, Ogawa J, Douet V, Xu Z, Kamikubo Y, Sakurai T, et al. Lamininal is essential for mouse cerebellar development. Matrix Biol. 2012; 31(1): 17-28.

24. Yoshida N, Ishii E, Nomizu M, Yamada Y, Mohri S, Kinukawa N, et al. The laminin-derived peptide YIGSR (Tyr-Ile-Gly-Ser-Arg) inhibits human pre-B leukaemic cell growth and dissemination to organs in SCID mice. Br J Cancer. 1999; 80(12): 1898.

25. Bilozur ME, Hay ED. Neural crest migration in 3D extracellular matrix utilizes laminin, fibronectin, or collagen. Developmental biol. 1988; 125(1): 19-33.

26. Iwamoto Y, Robey FA, Graf J, Sasaki M, Kleinman HK, Yamada Y, et al. YIGSR, a synthetic laminin pentapeptide, inhibits experimental metastasis formation. Science. 1987; 238(4830): 1132-4.

27. Hubbell JA, Massia SP, Desai NP, Drumheller PD. Endothelial cell-selective materials for tissue engineering in the vascular graft via a new receptor. Biotechnology (N Y). 1991; 9(6): 568-72.

28. Jun HW, West JL. Endothelialization of microporous YIGSR/PEG-modified polyurethaneurea. Tissue Eng. 2005; 11(7-8): 1133-40.

29. Huber M, Heiduschka P, Kienle S, Pavlidis C, Mack J, Walk T, et al. Modification of glassy carbon surfaces with synthetic laminin-derived peptides for nerve cell attachment and neurite growth. J Biomed Mater Res. 1998; 41(2): 278-88.

30. Tashiro Ki, Sephel G, Weeks B, Sasaki M, Martin G, Kleinman HK, et al. A synthetic peptide containing the IKVAV sequence from the A chain of laminin mediates cell attachment, migration, and neurite outgrowth. J Biol Chem. 1989; 264(27): 16174-82.
31. Ranieri JP, Bellamkonda R, Bekos EJ, Gardella JA Jr, Mathieu HJ, Ruiz L, et al. Spatial control of neuronal cell attachment and differentiation on covalently patterned laminin oligopeptide substrates. J DEV Neuro. 1994; 12(8): 725-35.

32. Massia SP, Holecko MM, Ehteshami GR. In vitro assessment ofbioactive coatings for neural implant applications. J Biomed Mater Res A. 2004; 68(1): 17786.

33. Li Q, Chau Y. Neural differentiation directed by self-assembling peptide scaffolds presenting lamininderived epitopes. J Biomed Mater Res A. 2010; 94(3): 688-99.

34. Cheng TY, Chen MH, Chang WH, Huang MY, Wang TW. Neural stem cells encapsulated in a functionalized self-assembling peptide hydrogel for brain tissue engineering. Biomaterials. 2012; 34: 2005-2016. 